\title{
Correction to: The Right to Play Versus the Right to War? Vulnerable Childhood in Lebanon's NGOization
}

\author{
Estella Carpi and Chiara Diana
}

\section{Correction to:}

Chapter 6 in: K. Cheney and A. Sinervo (eds.), Disadvantaged Childhoods and Humanitarian Intervention, Palgrave Studies on Children and Development, https://doi.org/10.1007/978-3-030-01623-4_6

In the original version of the book, affiliation "Université Libre de Bruxelles, Brussels, Belgium" in Chapter 6 should be changed to "AixMarseille University, OMAM-MSH Brussels, IREMAM, LabexMed". The correction chapter and the book have been updated with the change.

The updated version for this chapter can be found at https://doi.org/10.1007/978-3-030-01623-4_6

(C) The Author(s) 2019

K. Cheney and A. Sinervo (eds.), Disadvantaged Childhoods and Humanitarian Intervention, Palgrave Studies on Children and Development, https://doi.org/10.1007/978-3-030-01623-4_10 